\title{
Geometric ring annuloplasty for bicuspid aortic valve repair in a child
}

Ryan M. Wolsky, BS, ${ }^{\mathrm{a}}$ J. Scott Rankin, MD, ${ }^{\mathrm{b}}$ James M. Meza, MD, MSc, ${ }^{\mathrm{c}}$ G. Chad Hughes, MD, ${ }^{\mathrm{a}}$ and Joseph W. Turek, MD, PhD, ${ }^{\text {a,d }}$ Durham, NC, and Morgantown, WVa

From the a Division of Thoracic and Cardiovascular Surgery, Department of Surgery, Duke University Medical Center, Durham, NC; ${ }^{b}$ Department of Thoracic and Cardiovascular Surgery, West Virginia University, Morgantown, WVa; ${ }^{\mathrm{c}}$ Department of Surgery, Duke University Hospital, Durham, NC; and ${ }^{\mathrm{d}}$ Duke Pediatric \& Congenital Heart Center, Duke Children's Hospital, Durham, NC.

This work was supported by BioStable Science and Engineering, Inc, Austin Tex.

Disclosure: Dr Turek is a consultant for BioStable Science and Engineering, Inc, Austin, Tex. Dr Rankin is a minor equity holder in and a consultant for BioStable and has patents/royalties for Intra-annular Mounting Frame SPTO 15/845,775 (US Patent Number 8,163,011 B2). All other authors have nothing to disclose with regard to commercial support.

Received for publication Feb 18, 2019; revisions received June 11, 2019; accepted for publication June 20, 2019; available ahead of print Aug 5, 2019

Address for reprints: Joseph W. Turek, MD, PhD, Division of Thoracic and Cardiovascular Surgery, Duke University Medical Center, 2301 Erwin Rd, DUMC 3474, Durham, NC 27710 (E-mail: joseph.turek@duke.edu). J Thorac Cardiovasc Surg 2020;159:e135-7

$0022-5223 / \$ 36.00$

Copyright (C) 2019 by The American Association for Thoracic Surgery

https://doi.org/10.1016/j.jtcvs.2019.06.047

- Video clip is available online.

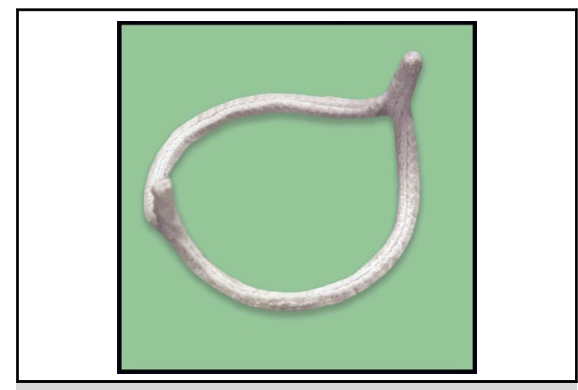

Geometric bicuspid annuloplasty ring used in this procedure.

\section{Central Message}

An insufficient pediatric bicuspid valve was repaired by geometric ring annuloplasty and leaflet reconstruction, remodeling commissures to $180^{\circ}$ and recruiting leaflet centrally to promote coaptation.

See Commentaries on pages e 139 and e141.

Ring annuloplasty has been used routinely for surgical repair of tricuspid and mitral valves for more than 35 years, and more recently, a similar ring has been developed for bicuspid aortic valve (BAV) repair. ${ }^{1}$ Annuloplasty rings restore normal size and geometry of the valve annulus, bring the native leaflets into better coaptation, and prevent future annular dilatation. In this article, the first case of a pediatric patient with a BAV and severe aortic insufficiency (AI) managed with internal ring annuloplasty is presented.

\section{CASE REPORT}

A murmur was discovered during a routine physical examination of an active, symptom-free 12-year-old boy (height, $159.6 \mathrm{~cm}$; weight, $58.7 \mathrm{~kg}$, body surface area, $1.6 \mathrm{~m}^{2}$ ). Cardiac Magnetic resonance imaging demonstrated AI with a $40 \%$ regurgitation fraction and severe left ventricular hypertrophy. A preoperative transthoracic echocardiogram showed a typical Sievers type $1 \mathrm{BAV}{ }^{2}$ with right-left commissural fusion, leaflet prolapse, and a large central coaptation gap.

At surgery, the dilated valve annulus sized to a $21-\mathrm{mm}$ diameter, and the noncoronary leaflet sized to a $19-\mathrm{mm}$ bicuspid ring (HAART 200 Aortic Annuloplasty Device; BioStable Science and Engineering, Austin Tex; Figure 1). The validated sizing strategy measured the nonfused leaflet free edge length with special ball sizers, and the length divided by 1.8 equaled the diameter of ring required for leaflet competence. The posts of the ring first were sutured to each subcommissural space with pledgeted horizontal mattress sutures (Video 1). Then, 2 transannular

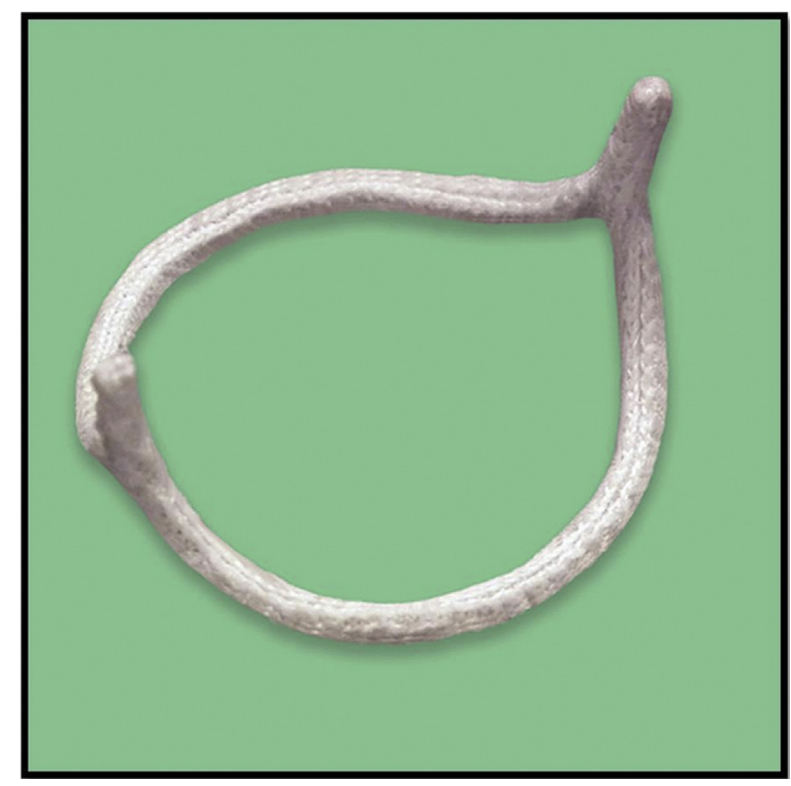

FIGURE 1. Bicuspid annuloplasty ring used in this patient. 


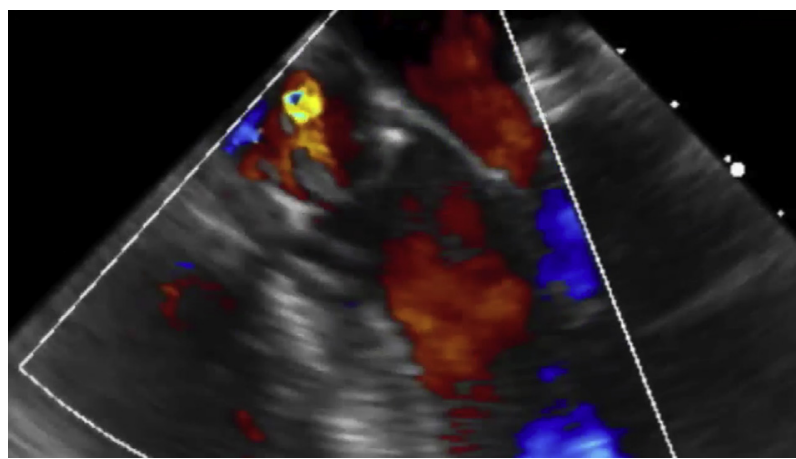

VIDEO 1. Repair of a bicuspid aortic valve with a geometric ring in a child. This video was presented at the European Congenital Heart Surgeons Association meeting, Lisbon, Portugal, Friday, June 1, 2018. Video available at: https://www.jtcvs.org/article/S0022-5223(19)31340-6/fulltext.

horizontal mattress sutures were placed through the sinus aspect of each leaflet annulus and looped around the ring to obtain a subannular position.

\section{Pre-Repair}
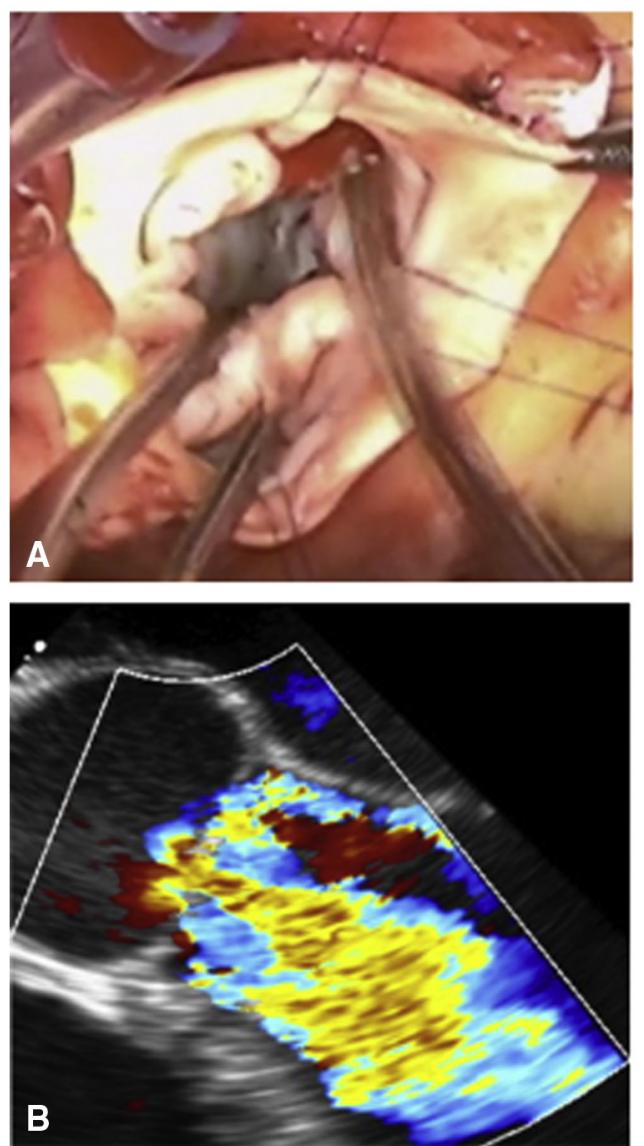

After the annuloplasty, the commissures were aligned to $180^{\circ}$, and both leaflets were moved centrally. Both leaflets still prolapsed as a result of unequal leaflet free-edge lengths, however, and the Schäfers leaflet reconstruction was used. ${ }^{3}$ Leaflet plication stitches were placed in the redundant noncoronary leaflet to raise it to a reference effective height of $8 \mathrm{~mm}$ (Video 1). Then, the cleft in the fused leaflet was closed with 3 simple sutures. This process brought the 2 leaflets into coaptation with equivalent freeedge lengths and effective heights, attaining good valve competence. After repair, transesophageal echocardiography showed good leaflet mobility and opening, no residual leak, and a $15-\mathrm{mm} \mathrm{Hg}$ mean systolic gradient (Figure 2). The patient's postoperative course was unremarkable, and he was discharged on the third postoperative day. He continues to do well, with no symptoms and were fully functional more than 1 year after surgery. Magnetic resonance imaging at 6 months showed mild AI (12\% regurgitant fraction) and mild aortic stenosis (peak velocity, $284 \mathrm{~cm} / \mathrm{s})$.

\section{Post-Repair}
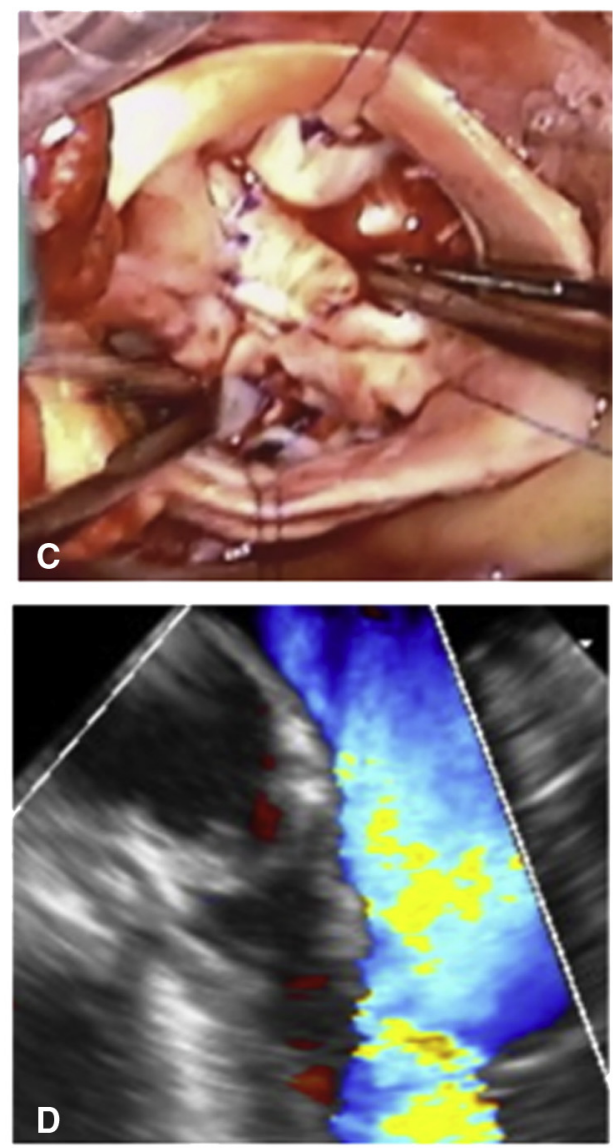

FIGURE 2. A, Prerepair appearance of type 1 bicuspid valve showing dysplastic incompetent leaflets. B, Prerepair echocardiogram showing severe aortic insufficiency. C, Postrepair valve appearance with good leaflet coaptation. D, Postrepair echocardiogram with a fully competent valve. 


\section{COMMENT}

Annuloplasty is well established for mitral and tricuspid reconstruction, and a new internal geometric annuloplasty ring has shown promise for BAV repair in adults. ${ }^{1}$ This case represents the first application of this technology to the pediatric population, but it seemed that repair principles were similar to those observed in adult valves. Objective reduction of annular diameter that is based on nonfused leaflet size is an advantage, and creation of $180^{\circ}$ commissures facilitates leaflet reconstruction. In adults, ring annuloplasty has been applicable to all types of bicuspid anatomy, and intermediate-term results have been excellent. ${ }^{4}$ Effectively recruiting the patient's leaflets to the midline for coaptation and primarily relying on native leaflet tissue are advantages, ${ }^{5}$ because all types of pericardial leaflet substitutes have significant failure rates. The results obtained in this initial pediatric application seem promising, but more experience and follow-up will be required for full validation. Pediatric aortic valve disorders are composed primarily of BAV disease and its variants, so this topic is of prime importance.

Postoperative results associated with valve replacement in children have been suboptimal. ${ }^{6}$ Reports of outcomes after bicuspid valve repair have suggested better results, but reintervention rates could be significant, sometimes as a result of late annular dilatation, ${ }^{7}$ which could be prevented by an annuloplasty ring. In patients undergoing BAV repair at a mean age of 9 years, freedoms from reintervention and replacement at 7 years were $80 \%$ and $81 \%$, respectively. At 7-years, however, more than a third of survivors had significant AI or valve stenosis. ${ }^{7}$ In the report by Siddiqui and colleagues, ${ }^{8} 35$ of 146 patients undergoing BAV repair required subsequent reintervention at a mean follow-up of
8 years, and 30 more had significant valve dysfunction without reoperation. Of the remaining patients, only $54 \%$ had freedom from more than moderate valvular stenosis at 10 years, with the number as low as $36 \%$ at 18 years. ${ }^{7}$ The 10-year freedom from any significant event was $60 \%$ for those without use of patch material, whereas nearly all those with pericardial patch repair had an adverse event-again emphasizing the need to use primarily native leaflet tissue in the repair. Ring annuloplasty thus may be a viable alternative for BAV repair in pediatric patients, in an attempt to improve on current results; however, experience with more types of defects and more follow-up will be required to establish long-term clinical efficacy more completely.

\section{References}

1. Mazzitelli D, Pfeiffer S, Rankin JS, Fischlein T, Choi YH, Wahlers T, et al. A regu lated trial of bicuspid aortic valve repair supported by geometric ring annuloplasty. Ann Thorac Surg. 2015;99:2010-6.

2. Sievers HH, Schmidtke C. A classification system for the bicuspid aortic valve from 304 surgical specimens. J Thorac Cardiovasc Surg. 2007;133:1226-33.

3. Schäfers HJ. Reconstruction of the bicuspid aortic valve. Oper Tech Thorac Cardiovasc Surg. 2007;12:2-13.

4. Rankin JS, Mazzitelli D, Fischlein T, Choi YH, Pirk J, Pfeiffer S, et al. Geometric ring annuloplasty for aortic valve repair during aortic aneurysm surgery: two-year clinical trial results. Innovations (Phila). 2018;13:248-53.

5. Rankin JS, Mazzitelli D, Fischlein T, et al. Bicuspid aortic valve repair using geometric ring annuloplasty: two-year clinical trial results. Ann Thorac Surg. 2019. In press.

6. Etnel JRG, Elmont LC, Ertekin E, Mokhles MM, Heuvelman HJ, RoosHesselink JW, et al. Outcome after aortic valve replacement in children: a systematic review and meta-analysis. J Thorac Cardiovasc Surg. 2016;151:143-52.e1-3.

7. d'Udekem Y, Siddiqui J, Seaman CS, Konstantinov IE, Galati JC, Cheung MM, et al. Long-term results of a strategy of aortic valve repair in the pediatric population. J Thorac Cardiovasc Surg. 2013;145:461-7; discussion 467-9.

8. Siddiqui J, Brizard CP, Konstantinov IE, Galati J, Wheaton G, Cheung M, et al. Outcomes after operations for bicuspid aortic valve disease in the pediatric population. Ann Thorac Surg. 2013;96:2175-83. 